\title{
DRUG ABUSE AMONG WORKERS ADMITTED TO MENOUFIYA POISONING AND ADDICTION CONTROL CENTER
}

\author{
By

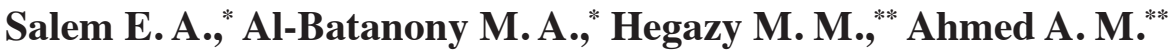 \\ From \\ * Public Health and Community Medicine Department; and ** Forensic Medicine and Clinical \\ Toxicology Department, Faculty of Medicine, Menoufiya University.
}

\begin{abstract}
:
Background: Drug or substance abuse reefers to the use of illicit (illegal) drugs and to the misuse of prescription or over-the-counter drugs. It is recognized as a serious risk to the health and safety of the user. Screening for substance abuse in workers is very important in the field of prevention and management of the problem of drug abuse. Objectives: This work aims at studying drug abuse among workers admitted to Menoufiya Poisoning and Addiction Control Center to illustrate the socio-demographic data of the drug abusers, the prevalence of drug abuse in different occupations and the impact of drug abuse on health and work. Methods: A total of seventy six worker patients admitted to Menoufiya Poisoning and Addiction Control Center throughout the year 2007 (out off the total number of admitted patients) were included in this study. The control group comprised one hundred and fifty two matching male subjects not known to be drug abusers. They were selected from volunteer blood donors in Menoufiya University blood bank. The studied population was divided according to occupation into professionals, skilled and unskilled workers. All participants were subjected to a predesigned questionnaire stressing on circumstances of drug abuse, clinical examination and investigations including chest x-ray, ECG, blood analysis for serum hepatitis B surface antigen ( $\mathrm{HBsAg}$ ) and hepatitis $\mathrm{C}$ antibodies $(\mathrm{HCAb})$. Results: Most of the studied individuals were skilled workers (46 persons, $60.5 \%$ ), followed by unskilled ones (22 persons, $28.9 \%$ ) and the least were professionals (8 persons, $10.6 \%)$. Skilled workers had a significantly higher prevalence of basic education than the others, working more than 12 hours/day at night shifts and living in families of more than three members. Trial was the main cause of drug abuse, friends were the persuading personsnel, pharmacies were the most prevalent sources of getting drugs and mixed types of drugs were taken by oral route during work shifts. Moreover, hepatitis $\mathrm{C}$ antibodies and abnormal
\end{abstract}




\begin{abstract}
X-ray films showing opacities and/or emphysematous chest were more frequent among drug abusers. Recommendations: As smoking is the first gate for addiction, smoking cessation is mandatory. Religious support and marriage are also recommended. Health education, counseling and effective employee assistance programs may help in preventing drug abuse in workplaces. Legislations for punishment of pharmacists selling these drugs without official prescription must be much more stiff.
\end{abstract}

Key words: Drug abuse, occupational factors, socio-demographic data.

\section{Introduction:}

Drug abuse is one of the serious problems that concern both the general population and the government. It affects young people in their productive years leading to many problems such as social maladaptation, decreased work productivity and job loss (Abdel-Gawad, 2008).

Prescription or over-the-counter drugs may be abused if the drug intake was more than the recommended dose, or if the drug was used for illegal purposes (www healthline.com, 2007).

Howland and colleagues in 2001 stated that alcohol and drug abuse and the associated hangovers impair coordination and the ability to perceive and respond to hazards, resulting in injury to the user and other innocent victims. In the workplace, drug abuse is associated with absenteeism, sleeping on the job, interpersonsal problems, dishonesty, and poor job performance (Miller et al., 2007). An employee's absence from the job impacts the cost of doing business, whether that cost is realized in the form of a planned leave such as paid vacation or through an unanticipated loss of productive labor like a work absence attributable to the debilitating effects of a hangover (Wiese et al., 2000).

Screening for substance abuse among workers is very important in the field of prevention and management of the problem of drug abuse. Studies on the prevalence of illicit drug use among workers are relatively scarce in the literature.

\section{Aim of the work:}

This work aims at studying the problem of drug abuse among workers admitted to Menoufyia Poisoning and Addiction Control Center and to illustrate:

a) The socio-demographic profile of drug -abused workers.

b) The distribution of drug abuse in different occupations.

c) The impact of drug abuse on health status and work production.

\section{Subjects and Method:}

The exposed group consisted of seventy six working male patients admitted to Menoufyia Poisoning and Addiction Con- 
trol Center throughout the year 2007 after exclusion of non-responders. The control group consists of one hundred and fifty two male subjects selected from volunteer blood donors in Menoufiya University blood bank who have never been drug abusers. Both exposed and control groups were matched for age, gender and socioeconomic standards.

Drug abuse workers were classified into three types of occupations; professionals (i.e.: engineers; 8 persons), skilled (i.e.: drivers; 46 persons) and unskilled workers (i.e.: manual workers; 22 persons). The purpose of the study was explained to the manager of the hospital, and participation in the study was voluntary. A consent form was signed by all participants and all collected personsal information was treated confidentially. The study was approved by the Ethics Review Committee of Menoufiya University.

\section{All participants were subjected to the}

\section{following:}

a) A pre-designed questionnaire stressing on socio-demographic data, family circumstances, present and past occu- pational history and circumstances of drug abuse.

b) Clinical examination including general as well as local examination of the eye, mouth, chest, heart and abdomen.

c) Investigations in the form of chest $\mathrm{X}$ ray, ECG, blood analysis for hepatitis B surface antigen ( $\mathrm{HBsAg}$ ) and hepatitis $\mathrm{C}$ antibodies (HCVAb) by third generation ELISA.

The drug screening was done by toxilab incorporated-irivine (CA 92718. Module 1 Cat. No - 151). Two toxi-lab tubes were used for extraction, one for basic and the other for acidic drugs. Toxi-lab developing solution; Toxi-lab dip for A and B. The rate of flow and colour developed compared with Toxi-lab text (Henry, 1991).

The data were collected, tabulated and statistically analyzed by an IBM personsal computer using the statistical package SPSS version 13. Qualitative data were expressed as number and percentage (No \& \%) and analyzed by applying chi-square $\left(\chi^{2}\right)$ test at $5 \%$ level of significance. 
Salem E. A. et al.,

Results:

Table (1): Socio-demographic characteristics of the studied workers.

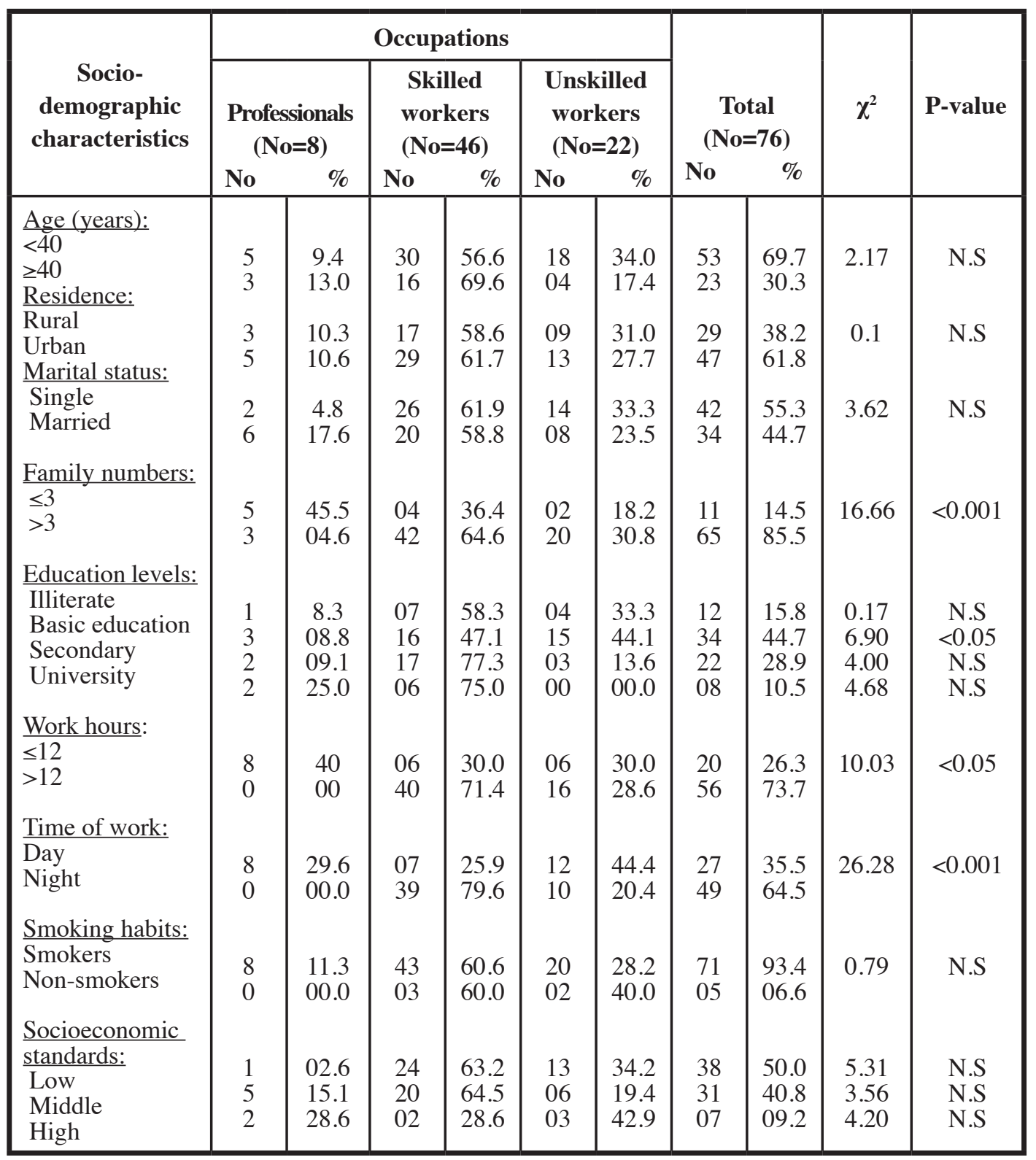

N.S: non-significant 
Table (2): Data related to drug abuse among the studied workers.

\begin{tabular}{|c|c|c|c|c|c|c|c|c|c|c|}
\hline \multirow{3}{*}{$\begin{array}{l}\text { Data related to } \\
\text { drug abuse }\end{array}$} & \multicolumn{6}{|c|}{ Occupations } & & & \multirow{3}{*}{$\boldsymbol{\chi}^{2}$} & \multirow{3}{*}{ P-value } \\
\hline & \multicolumn{2}{|c|}{$\begin{array}{l}\text { Professionals } \\
(\mathrm{No}=8)\end{array}$} & \multicolumn{2}{|c|}{$\begin{array}{c}\text { skilled } \\
\text { workers } \\
(\mathrm{No}=46)\end{array}$} & \multicolumn{2}{|c|}{$\begin{array}{c}\text { Unskilled } \\
\text { workers } \\
(\mathrm{No}=22)\end{array}$} & \multicolumn{2}{|c|}{$\begin{array}{c}\text { Total } \\
(\text { No=76) }\end{array}$} & & \\
\hline & No & & No & & & & & & & \\
\hline Causes: & 1 & 25.0 & 9 & 21.7 & 04 & 18.2 & 14 & 18.4 & 0.23 & N.S \\
\hline$\overline{\text { Anxiety }}$ & 1 & 00.0 & 02 & 02.2 & 00 & 0.00 & 03 & 03.9 & 2.47 & N.S \\
\hline Fatigue & 6 & 75.0 & 35 & 76.1 & 18 & 81.8 & 59 & 77.6 & 0.32 & N.S \\
\hline Trial & & & & & & & & & & \\
\hline Persuading: & 1 & 12.5 & 05 & 06.5 & 02 & 09.1 & 08 & 10.5 & 0.09 & N.S \\
\hline Pharmacists & 7 & 87.5 & 41 & 89.2 & 20 & 90.9 & 68 & 89.5 & & \\
\hline Friends & & & & & & & & & & \\
\hline Source of drugs: & & & & & & & & & & \\
\hline Pharmacies & 8 & 100.0 & 38 & 82.6 & 20 & 90.9 & 66 & 86.8 & 2.25 & N.S \\
\hline Friends & 0 & 000.0 & 08 & 15.2 & 02 & 01.3 & 10 & 13.2 & & \\
\hline Routes of intake: & & & & & & & & & & \\
\hline Oral & & & & & & & & & & \\
\hline Combinations* & 8 & 100.0 & 30 & 65.2 & 17 & 77.3 & 55 & 72.4 & 4.5 & N.S \\
\hline & 0 & 000.0 & 16 & & 05 & 22.7 & 21 & 27.6 & & \\
\hline Time of intake in & & & & & & & & & & \\
\hline time: & & & & & & & & & & \\
\hline -before & & & & & & & & & & \\
\hline -during & 1 & 12.5 & 05 & 08.7 & 7 & 31.8 & 13 & 15.8 & 4.74 & N.S \\
\hline -after & 5 & 52.5 & 21 & 45.7 & 8 & 36.3 & 34 & 44.8 & 1.66 & N.S \\
\hline & 2 & 25.0 & 20 & 45.7 & 7 & 31.8 & 29 & 39.4 & 1.51 & N.S \\
\hline
\end{tabular}

* Combination of oral and injection or snuffing. 
Table (3): Investigations carried out among the studied workers.

\begin{tabular}{|l|c|c|}
\hline \multirow{2}{*}{ Investigations } & \multicolumn{2}{|c|}{ Workers with drug abuse (n=76) } \\
& No & \\
\hline *Abnormal x-ray & 21 & 27.6 \\
"Abnormal ECG & 13 & 17.1 \\
HCVAb & 27 & 35.5 \\
HBsAg & 2 & 2.6 \\
+ve both anti HCV & 1 & 1.3 \\
and HBsAg & & \\
\hline
\end{tabular}

* In the form of any opacities and/or emphysematous chest.

\# In the form of any type of arrhythmias.

Table (4): Frequency Distribution of effects related to drug abuse among both drug abusers and control groups.

\begin{tabular}{|c|c|c|c|c|c|c|c|c|}
\hline \multirow{4}{*}{$\begin{array}{l}\begin{array}{c}\text { Effects related to drug } \\
\text { abuse }\end{array} \\
\text { Work effects: } \\
\text {-job accidents. } \\
\text {-absenteeism (days). }\end{array}$} & \multicolumn{2}{|c|}{$\begin{array}{c}\text { Drug abuse } \\
\text { workers } \\
(\mathrm{No}=76)\end{array}$} & \multicolumn{2}{|c|}{$\begin{array}{c}\text { Controls } \\
(\mathrm{No}=152)\end{array}$} & \multicolumn{2}{|c|}{$\begin{array}{c}\text { Total } \\
(\mathrm{No}=228)\end{array}$} & \multirow[t]{2}{*}{$\chi^{2}$} & \multirow[t]{2}{*}{ P-value } \\
\hline & & & & & No & $\%$ & & \\
\hline & & & & & & & & \\
\hline & $\begin{array}{l}15 \\
27\end{array}$ & $\begin{array}{l}68.2 \\
71.1\end{array}$ & $\begin{array}{l}07 \\
11\end{array}$ & $\begin{array}{l}31.8 \\
28.9\end{array}$ & $\begin{array}{l}22 \\
38\end{array}$ & $\begin{array}{l}09.6 \\
16.7\end{array}$ & $\begin{array}{l}13.31 \\
29.19\end{array}$ & $\begin{array}{l}<0.001 \\
<0.001\end{array}$ \\
\hline Health effects: & & & & & & & & \\
\hline -Impaired $\mathrm{m}$ & 30 & 71.4 & 12 & 28.6 & 42 & 18.4 & 33.62 & $<0.001$ \\
\hline -impaired sexual activity & 23 & 57.5 & 17 & 42.5 & 40 & 17.5 & 12.75 & $<0.001$ \\
\hline -disturbed sleep. & 24 & 68.6 & 11 & 31.4 & 35 & 15.4 & 23.1 & $<0.001$ \\
\hline -anorexia. & 19 & 67.9 & 09 & 32.1 & 28 & 12.3 & 17.12 & $<0.001$ \\
\hline -anxiety. & 37 & 63.8 & 21 & 36.2 & 58 & 22.4 & 32.48 & $<0.001$ \\
\hline Socio-economic troubles: & 21 & 56.8 & 16 & 43.2 & 37 & 16.2 & 10.9 & $<0.001$ \\
\hline
\end{tabular}




\section{Percentage of workers used drugs in relation to total admitted drug abusers in the year 2007}

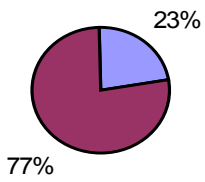

$\square$ workers used drugs $\square$ total admitted drug abusers
Figure (1): Percentage of drug abuse among workers in relation to the total drug abusers admitted in the year 2007 according to Menoufiya Poisoning and Addiction Control Center.
Figure (2): Distribution of drug abusers according to their occupation in the current study.

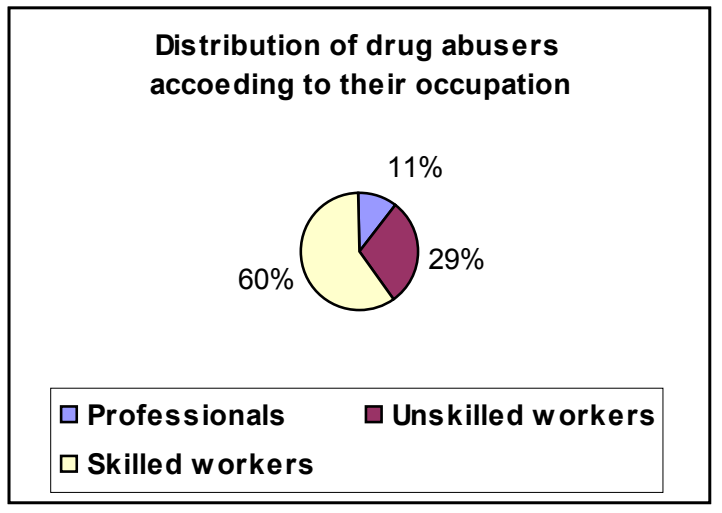

Ferquency distribution of different types of drugs among drug abusers

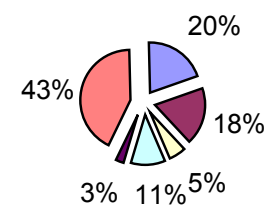

\begin{tabular}{|lll|}
\hline$\square$ Opioids $\quad \square$ Sedatives & $\square$ Hypnotics \\
$\square$ Hallucinogens & $\square$ Stimulants & $\square$ Mixed drugs \\
\hline
\end{tabular}

Figure (3): Frequency distribution of different types of drugs among drug abusers. 
Out of 323 total admitted drug abusers to Menoufiya Poisoning and Addiction Control Center throughout the year 2007 (including students, workers and un-employed personsnel), seventy six drug abuse workers were the subjects of this study (Figure 1). Most of them (60.5\%) were skilled workers followed by unskilled ones $(28.9 \%)$ and the least were professionals (10.6\%) (Figure 2).

The most prevalent age group among drug abusers was less than 40 years $(69.7 \%)$. About two thirds of skilled workers were single $(61.9 \%)$ with basic level of education $(47.1 \%)$ and living within families containing more than three members $(64.6 \%)$. Moreover, skilled workers showed significantly higher prevalence of working hours more than twelve hours/day (71.4\%) at night shifts (79.6\%). Most of the studied cases were smokers $(93.4 \%)$ with low socio-economic levels (50\%), mainly from urban areas (61.8\%) (table 1).

Trial was the main cause of drug abuse among all cases (77.6\%). The majority of cases reported the persuasion of their friends $(89.5 \%)$, while pharmacies being the most prevalent source of drugs (86.8\%). The routes of drug intake were mainly oral (72.4\%), followed by a combination of oral and injection or snuffing among others $(27.6 \%)$. About $44.8 \%$ of workers took drugs at work. There was no significant difference between the studied groups regarding data related to drug intake (table 2).

Most cases used mixed types of drugs (43.4\%), while $19.7 \%$ took opioids followed by sedatives $(18.4 \%)$, hallucinogens (10.5\%), hypnotics (5.2\%) and lastly stimulants (2.6\%) (Figure 3). Abnormal chest $\mathrm{x}-$ rays showing opacities and/or emphysematous chest were observed in $27.6 \%$ of cases. Abnormal ECG in the form of any type of arrhythmias was found between $17.1 \%$. Sero-positive cases for HCVAb constituted about $35.5 \%$ (table 3 ).

On comparing drug abusers with control group regarding the effects of drug abuse, the former revealed significantly higher prevalence of work absenteeism $(71.1 \%)$ and recorded accidents $(68.2 \%)$ than the latter. The frequency of socio-economic troubles $(56.8 \%)$ and reported health effects, in the form of impaired memory (71.4\%), impaired sexual activity (57.5\%), disturbed sleep (68.6\%), anorexia (67.9\%) and anxiety (63.8\%), were all significantly higher among drug abusers than the control group (table 4).

\section{Discussion:}

Workers in certain occupations may be at a higher risk of being driven into drug abuse. In this study, among cases admit- 
ted to Menoufiya Poisoning and Addiction Control Center throughout the year 2007, skilled workers showed a higher prevalence of drug abuse (46 persons, 60.5\%), while professionals showed the lowest prevalence ( 8 persons, $10.5 \%$ ). These results agree with that of Francis et al., (1995), who reported that skilled workers, especially drivers, showed the most prevalent spread of substance abuse. This finding may, principally, be due to their low basic educational level $(47.1 \%)$ and/or that $64.5 \%$ of them fall within middle socio-economic level; thus had fair income. In this study, skilled workers showed a higher prevalence of drug abuse while professionals showed the lowest prevalence coincides with Larson et al., (2007) who stated that workers in food service and construction occupations showed a higher prevalence of illicit drug use than other occupational groups, while those in protective service, community and social services, and education and related services showed the lowest prevalence rates.

No females presented in this study, this is not surprising as in our society, it is considered uncommon for a family if one of her female members was reported to be a drug abuser.

The age of drug abusers in this study were less than 40 years $(69.7 \%)$ who are in the work productivity age. This result agreed with the study carried out by Al Kott (1991) who mentioned that most drug abusers in Egypt tend to be men, 20 to 40 years of age .

While the National Survey on Drug Use and Health (NSDUH) 2006, found that among full-time employed personss diagnosed with a substance use disorder, those aged 18-25 had the highest rates of substance use disorder, relative to those in other age categories. The difference between the latter and this study's result, may be attributed to the fact that, in Egypt, full time-employed workers aged from 18-25 years represent a very low prevalence of all employees.

Drug abused workers were mostly single $(55.3 \%)$. This means that marriage with its responsibilities may be a barrier against drug abuse as it gives psychological or emotional stability to the persons. Most abusers were coming from urban areas (61.8\%). This may be attributed to modern style of life, wide spread entertainment places, the presence of foci of aggregation of abusers and sites for drug sale. This agreed with $\mathrm{Al}$ Kott (1991) who found that drug abuse is more common in the urban areas than in rural and semi-rural areas in Egyptian workers.

The present study revealed that drug abuse was more frequent among smokers 
(93.4\%) than non-smokers (6.6\%), coinciding with the findings of Soueif et al., (1985), as smoking was considered the first step for drug abuse and addiction.

Most of drug abusers worked for more than 12 hours /day $(73.7 \%)$ and at night shifts $(64.5 \%)$ as this time enhance abusers grouping. About $44.8 \%$ of abusers took drugs during work time while only $39.4 \%$ use them after work to relieve tiredness.

The study demonstrated that $77.6 \%$ of cases abused drugs as a trial, while $18.4 \%$ due to psychological troubles. Friends were the personss who persuaded the patients start drug abuse $(89.5 \%)$. This coincides with Flisher et al., (1993) who found that starting drug intake most often occurs on some social occasions or in the company of friends. They also found that bad friends played a major factor by imitating, experimentation and co-partnership. The role of a group leader who attracts vulnerable cases by different ways without any cost comes to be gradually and informally established.

Different drug combinations were used by drug abusers (43.4\%) followed by opioids (19.7\%) then sedatives (18.4\%). These drugs are mainly present in medicinal preparations that are cheap and at reach hence the importance of strict laws for punishing pharmacists who sell these drugs without any official prescription. Cocaine is an increasingly popular drug used at the workplace, giving the users a false feeling of better and faster performance at work. Cocaine is snorted rather than smoked and gives off no such odor as marijuana does (Soueif et al., 1985).

In this study, users have devised ways to carry the drug to their workplace without being detected through empty squeeze-bottle medication used to relieve sinus congestion. By carrying it in the pocket, it remains ready for sniffing as it evaporates at $30^{\circ} \mathrm{C}$, whereas the normal body temperature is $37^{\circ} \mathrm{C}$ (Al Kott, 1991).

Among professionals, 25.5\% abused opium followed by sedatives (12.3\%); while skilled workers abused sedatives $(19.6 \%)$ followed by opium (15.2\%).

These results are in agreement with that detained in a sample survey of 5,108 Egyptian workers where cannabis and opium $(15.1 \%)$ were drugs of abuse among skilled workers followed by psychoactive drugs $(2.5 \%)$. As for the unskilled workers, the prevalence of cannabis and opium is only $7.5 \%$ and psychoactive drugs is $0.7 \%(\mathrm{Al}$ Kott, 1991).

Combination of drug intake by the oral route and injection or snuffing was $27.6 \%$, as for the overall prevalence of HCVAb, 
and $\mathrm{HBsAg}$ among studied workers, it was found to be $35.5 \%$ and $2.6 \%$; respectively. This was attributed to the sharing of same syringes during intake of drugs and to the poor health practice. Similar results were obtained by Todd et al., in 2007 who found that the prevalence of $\mathrm{HCV}$, and $\mathrm{HBsAg}$ among drug abusers in Afghanistan was $36.6 \%$ and $6.5 \%$; respectively.

On comparing studied workers and controls, it was observed that drug abuses showed a significantly higher prevalence of health effects, socio-economic troubles, recorded accidents at work and repeated work absenteeism. Drug abuse leads to lower productivity, raised insurance costs and reduced profits. On top of this, employee carry the risk of losing their jobs and even losing their live as the use of drugs threatens the physical and/or mental health, inhibits personsal relationships, diminishes the ability to meet family, social or vocational obligations.

Additionally, the National Household Survey on Drug Abuse [NHSDA] (2002) found that drug abusers are far less productive carrying a higher risk of losing their jobs. They are:

- Ten times more likely to miss work.

- Three and half times more likely to be involved in job accidents.
- Five times more likely to file a worker's claim.

- Thirty three percent less productive.

- Responsible for three times higher expenses on health care.

-Responsible for forty percent of all industrial fatalities.

Based on the results of this study, it may be concluded that smoking cessation is mandatory as smoking is the first gate for addiction. Religious support and marriage are also recommended. Education, counseling and effective employee assistance programs for hazards of drug abuse are important for prevention of drug abuse among workers at the workplaces. Frequent screening for substance abuse among workers is very important to achieve proper prevention and management of the problem. A good protocol for treatment by dealing with addict as a sick persons and not a criminal one is essential. Finally, warnings on packages or accompanying leaflet information are required to safeguard the users of preparations containing narcotic drugs in addition to the punishment of pharmacists who sell these drugs without official prescription.

\section{References:}

1. Abdel-Gawad, T.M. (2008): "Facts of drug abuse in Egypt" http://www.isamweb.com/pages/pdfs/ebook\%20Issue\%203/Gawad.pdf 
2. Al Kott, A. (1991): "Drug and Substances Abuse Among Egyptian Workers- Model Programmes for the Prevention of Drug and Alcohol Abuse Among Workers and their Families." http://www.drugabusestatistics.samhsa.gov/ facts.cfm

3. Flisher, A. J., Ziervogel, C. F. and Chalton, D. O. (1993): "Risk-taking behaviour of Cape Peninsulea high school students, Part V. Drug Use". South African Med. J., 83(7):483-485.

4. Francis, M., Eldemire, D. and Clifford, B. (1995): "A pilot study of alcohol and drug related traffic accidents and death in two Jamaican Parishes". West Ind Med. J., 76(5):99-101.

5. Henry, J.B. (1991): Toxicology and therapeutic drug monitoring in clinical diagnosis and management by laboratory methods. 18th edition, W.B. Saunders Company, Philadelphia, London. 351-54.

6. Howland, J., Rohsenow, D.J., Cote, J., Gomez, B., Mangione, T.W., and Laramie, A.K. (2001): "Effects of low-dose alcohol exposure on simulated merchant ship piloting by maritime cadets". Accid. Analy. Preven. 33(2): 257-65.

7. Larson, S.L., Eyerman, J., Foster, M.S. and Gfroerer, J.C. (2007): Worker substance use and workplace policies and programs. In: Substance abuse and mental health services administration, by Rockville, M.D. 5th edition, DHHS Publication, 4268-73.
8. Miller T.R.,Zaloshnja E and Spicer R.S. (2007): "Effectiveness and benefit-cost of peer-based workplace substance" Accid. Analy. Preven. 39: 565-73.

9. National Institute on Alcohol Abuse and Alcoholism [NIAAA] (1997):

10. "Ninth special report to the U.S. Congress on alcohol and health. US Department of Health and Human Services". NIH Pub. 97:401.

11. National Household Survey On Drug Abuse (NHSDA) (2002): "Substance use, dependence or abuse among full-time workers". http://www. drugabusestatistics.samhsa.gov/facts.cfm

12. National Survey on Drug Use and Health (NSDUH) Report (2006): "Substance use disorder and serious psychological distress employment status" 38:12-5.

13. Soueif, M. I., Darweesh, Z. A. and Taha, H.S (1985): "The association between tobacco smoking and use of other psychoactive substances among Egyptian male students". Drug Alcohol Depend. 5(1): 47-56.

14. Todd, S., Abed, M.S. and Strathdee, A. (2007): "HIV, hepatitis C, and hepatitis B infections and associated risk behavior in injection drug users, Kabul, Afghanistan” Emerg. Infect. Disease. J., 13(9):42-51.

15. Wiese J. G., Shlipak M. G. and Brower W. S. (2000): "The alcohol Hang-over". Ann Int. Med. 132:897-902.

16. www healthline.com, 2007 